\title{
BMJ Global Heath Paradigms, policies and people: the future of primary health care
}

\author{
Susan B Rifkin (1D) 1,2
}

To cite: Rifkin SB. Paradigms, policies and people: the future of primary health care. BMJ Global Health 2020;5:e02254. doi:10.1136/ bmjgh-2019-002254

Received 20 December 2019 Revised 10 January 2020 Accepted 13 January 2020

Check for updates

(c) Author(s) (or their employer(s)) 2020. Re-use permitted under CC BY-NC. No commercial re-use. See rights and permissions. Published by BMJ.

${ }^{1}$ Distance Learning, London School of Hygiene and Tropical Medicine, London, UK ${ }^{2}$ Health Systems, Management and Policy, Colorado School of Public Health, Aurora, Colorado, USA

Correspondence to

Dr Susan B Rifkin;

sbrifkin@gmail.com
In a recent article in BMJ Global Health, Kraef and Kallestrup ${ }^{1}$ presented a comprehensive review of the potentials and challenges to primary health care (PHC) since its inception in the Alma Ata Declaration in $1978^{2}$ and its latest iteration in the Astana Declaration in $2018 .^{3}$ The challenges include threats such as disease outbreaks, conflicts and resulting insecurity, lack of support and commitment by politicians, inadequate monitoring and evaluation approaches and tools, weak financial systems, weak support of health professionals and their organisations and poor responses to community needs. These challenges are well documented and long standing. They are also difficult to overcome.

It can be argued that there is one major obstacle to meeting these challenges. It is the restricted approach for identifying problems and how possible subsequent improvements are most often investigated and presented. WHO defined health as 'the state of complete physical, mental and social well-being and not merely the absence of disease or infirmity'. ${ }^{4}$ The Alma Ata declaration provided rhetoric and idealism to put meat on the bones of the WHO definition. However, the last 40 years have tended to focus on the microcosms such as disease eradication, health service delivery and most recently physical and mental rehabilitation. This focus has resulted in addressing health challenges in silos that block the critical importance of viewing improvements in health in the much wider environment of social, political and economic contexts.

This narrow and siloed focus can be seen in two recent special issues of BMJ Global Health devoted to examining the potentials and challenges presented in the PHC approach to heath (May 2018, Volume 3, Suppl $3 ;{ }^{5}$ September 2019, Volume 4, Suppl 8). ${ }^{6}$ Both issues have articles looking in depth at the past and future of PHC, some in great geographic or subject detail. However, none address the wider context in which their research suggestions can be implemented on a global replicable scale. Their narrow focus defines problems and successes most often in numbers. They do not present a broader framework that includes a wider analysis of the context and the processes of change.

Achieving health in line with its WHO definition is only possible when there is a shift in paradigm (with paradigm defined as 'a philosophical and theoretical framework of a scientific school or discipline within which theories, laws and generalisations and experiments performed in support of them is formulated ${ }^{7}$ - a concept presented by Thomas Kuhn in his book The Nature of Scientific Revolutions.

In applying this concept to health policy and health provision in the case of $\mathrm{PHC}$, the shift in paradigm needs to move from viewing health as a result of a linear, predictive set of biomedical interventions to viewing it as a dynamic, iterative process that include social, political and economic factors. Taking actions to achieve health as defined by WHO requires a change in the conceptualisation of its goals and objectives including:

1. Differentiating between PHC and primary care, the delivery of a health service. ${ }^{8}$ In a 2008 publication, WHO's Commission on the Social Determinants of Health states 'The Alma Ata Declaration promoted PHC as its central means towards good and fair global health-not simply health services at the primary care level (though that was important), but rather a health system model that acted also on the underlying social, economic and political causes of poor health'. ${ }^{8}$ Editorials in the May 2018 special issue of BMJ Global Health focusing on PHC entitled 'Reflections on family medicine and PHC in sub-Saharan Africa' and the September 2019 special issue, entitled 'What kind of evidence do we need to strengthen and PHC in the 21st century' 10 note the importance of issues of leadership, governance, equity and universal coverage. However, these critical discussions 
are in the context of improving health service delivery. Other articles in these two issues used the terms PHC and primary care interchangeably and kept the discussion confined to PHC within the biomedical framework.

2. Creating priorities and financial structures that support the Health in All Policies ${ }^{11}$ approach rather than focusing on healthcare and health education. Policymakers and governments have struggled to implement the wider context of PHC addressing social determinants. Because specific interventions that were universal and were able to be applied globally with predictable outcomes to improve health were illusive, Universal Health Coverage (UHC) proved to be a unifying approach to address both major barriers to health provision and to support the UN's Sustainable Development Goals. ${ }^{12}$ The Astana Declaration in 2018 celebrated the 40th anniversary of Alma Ata and put forward UHC as a rallying point to move forward. However, this focus rather than widening efforts to understand health in the social determinant context again focused on promoting an intervention. ${ }^{13}$ Its value was that it provided clear measurable outcomes in both economic and population health improvements. Its weakness was that it put health improvements into another silo and raised questions about identifying priorities for what interventions/services would be covered, allocating the required money in the dominance of present market economies and creating and supporting structures for financing especially in lowincome and middle-income countries. ${ }^{14}$

3. Training public health professionals to be experts and facilitators of community-led health initiatives by recognising and acting on evidence that (i) communities are not homogenous, (ii) context is critical to understanding reasons for success and/or failure of specific interventions, (iii) evaluation is a not linear analysis of successes and failures but is an iterative process that often is not generalisable. Community participation along with equity was one of the two key principles of Alma Ata. ${ }^{2}$ It has arguably been the most challenging to address in PHC. ${ }^{15}$ Public health professionals are trained to investigate the reasons for a disease or health problem and to identify an intervention to address this problem. Medical professionals deal mainly with individuals. Public health officials deal with populations. Both groups are valued for their expertise in their fields. Neither has been trained to involve their respective subjects in decisions about the solution to the problem. Very few have reached out to professionals who have expertise in interactive decision making such as psychologists and/or community development professionals. The consequences of this limitation include: a lack of respect for those without formal training in the field who are better informed about specific situations; an inability to develop a mutual dialogue about a problem even if the non-professional has more experience with the problem; a narrow interpretation of a health problem that does not take into account the wider context (such as poverty or poor education) and influence from the medical sciences to use Randomised Controlled Trials as the gold standard for evaluating i outcomes. Community participation in health has been increasingly recognised as a process not an intervention. ${ }^{16}$ Integration of this wider approach challenges the traditional ways of delivering and assessing healthcare and their results.

The future of achieving PHC as envisioned by the Alma Ata Declaration requires a paradigm shift that depends on policies and people. It depends on eliminating the continuing confusion between PHC and primary care, creating institutional structures and committed financing to address health improvements in the context of social, political and economic realities and the most important issues of the day such as climate change, and embedding specific mechanisms to include lay people and communities in decisions about healthcare that reflect the context and social determinants of their specific environment.

Kuhn used the example of the shift in acceptance of the sun (rather than the earth) as being the centre of the universe to explain how paradigms shift. He noted that there are no eureka moments, but a long trail of trial and tribulations lasting several centuries. However, small successes in investigations and facts allow the shift to take place. At the present time, there are several contributions in understanding health improvements that add to the possibility of that paradigm shift in health.

One such contribution is the increasing use of qualitative research to understand how, why, and under what circumstances those affected by health conditions and inequities react to these situations and suggest new approaches to address them. Another is the creation of mechanisms to include communities affected by poor health such as the training of Community Health Workers (CHW) and local community health committees as described by Ved et al in Supplement $8 .{ }^{17} \mathrm{~A}$ third is the galvanising and expansion of local and global nongovernment organisations such as the Peoples' Health Movement and COPASAH (Community of Practitioners on Accountability and Social Action in Health) advocating and acting on demands for social accountability by health service providers and for wider action to address issues of equity including the social determinants and community participation.

Kuhn noted that paradigm changes are not inevitable. Paradigm change depends on people accepting a new interpretation of events and putting in place policies to accommodate this new interpretation. Opposition by those who hold the old paradigm is very strong and must be overcome. A new paradigm can only emerge when the old one is rejected. Two cannot exist simultaneously. Kuhn's example of the recognition of the sun as being at the centre of the universe reflects the long and arduous path to acceptance. Will PHC be able to stay the course? 
Acknowledgements Meredith Fort and Seye Abimbola read the manuscript and gave me critical suggestions for improvement.

Funding The authors have not declared a specific grant for this research from any funding agency in the public, commercial or not-for-profit sectors.

Competing interests None declared.

Patient consent for publication Not required.

Provenance and peer review Not commissioned; internally peer reviewed.

Data availability statement № additional data are available.

Open access This is an open access article distributed in accordance with the Creative Commons Attribution Non Commercial (CC BY-NC 4.0) license, which permits others to distribute, remix, adapt, build upon this work non-commercially, and license their derivative works on different terms, provided the original work is properly cited, appropriate credit is given, any changes made indicated, and the use is non-commercial. See: http://creativecommons.org/licenses/by-nc/4.0/.

ORCID iD

Susan B Rifkin http://orcid.org/0000-0001-5482-7829

\section{REFERENCES}

1 Kraef C, Kallestrup P. After the Astana declaration: is comprehensive primary health care set for success this time? BMJ Glob Health 2019;4:e001871.

2 World Health Organization. Primary health care: report of the International Conference on primary health care Alma Ata, USSR, 6-12. Geneva, Switzerland, 1978.

3 World Health Organization. Declaration on primary health care, 2018. Available: https://www.who.int/primary-health/conference-phc/ declaration [Accessed 2 Dec 2019].

4 World Health Organization. Supplement to basic documents. constitution of the world Health organization, 2006. Available: http:// www. who. int/ governance/ eb/ who_ constitution [Accessed 2 Dec 2019].

5 Topp SM, Abimbola S. Call for papers - the Alma Ata Declaration at 40: reflections on primary healthcare in a new era. BMJ Glob Health 2018;3:e000791.
6 Strengthening primary health care through research: Prioritized knowledge needs to achieve the promise of the Astana Declaration. BMJ Global 2019;4.

7 Kuhn TS. The structure of scientific revolutions. Chicago: University of Chicago Press, 1962.

8 Commission on the Social Determinants of Health. Closing the gap in a generation: health equity through action on the social determinants of health: final report of the Commission on social determinants of health. Geneva, Switzerland: World Health Organization, 2008: P.33.

9 Mash R, Howe A, Olayemi O, et al. Reflections on family medicine and primary healthcare in sub-Saharan Africa. BMJ Global Health 2018;3:e000662.

10 Hirschhorn LR, Langlois EV, Bitton A, et al. What kind of evidence do we need to strengthen primary healthcare in the 21st century? BMJ Glob Health 2019;4:e001668.

11 World Health Organization. Helsinki statement: framework for country action, 2014. Available: https://apps.who.int/iris/bitstream/ handle/10665/112636/9789241506908 eng.pdf;jsessionid=92C0 B493B17C1A45518F6B250EBD7C35?sequence=1 [Accessed 29 Nov 2019].

12 United Nations Development Program. Human development report 2019. sustainable development goals. Available: https://www.undp org/content/undp/en/home/sustainable-development-goals.html [Accessed 29 Nov 2019].

13 Rifkin SB. Alma Ata after 40 years: primary health care and health for All-from consensus to complexity. BMJ Glob Health 2018;3:e001188.

14 Palagyi A, Dodd R, Jan S, et al. Organisation of primary health care in the Asia-Pacific region: developing a prioritised research agenda BMJ Glob Health 2019;4:e001467.

15 Lawn JE, Rohde J, Rifkin S, et al. Alma-Ata 30 years on: revolutionary, relevant, and time to revitalise. The Lancet 2008;372:917-27.

16 Nolte E, Merkur S, Anell A. Achieving Person-Centered health systems; evidence, strategies and challenges. Cambridge: Cambridge University Press. In Press.

17 Ved R, Sheikh K, George AS, et al. Village health sanitation and nutrition committees: reflections on strengthening community health governance at scale in India. BMJ Global Health 2018;3:e000681. 